\title{
Akarsu Akım Verilerinin Bulanık Mantık Yöntemiyle Tahmini: Bendimahi Çayı Örneği
}

\author{
Nadire Üçler \\ Van Yüzüncü Yıl Üniversitesi, Van Meslek Yüksek Okulu, Inşaat Bölümü,Van, Türkiye. \\ nadireucler@yyu.edu.tr \\ 04322251414
}

\section{Özet}

Bu çalışmada; Van İli, Muradiye İlçesinde yer alan Bendimahi Çayına ait aylık ortalama akım verileri aynı ilçenin aylık ortalama sıcaklık ve aylık toplam yağış verilerine bağlı olarak Bulanık Mantık Yöntemi ile tahmin edilmiştir. Sadece sıcaklık, sadece yağış ve hem sıcaklık hem yağış verilerinin girdi olarak kullanıldığı ve akım değerinin çıktı olarak seçildiği üç farkı model oluşturulmuştur. Modeller, 1970-2008 yılları arasına ait veriler kullanılarak hazırlanmış, 2009, 2010 ve 2011 yıllarına ait veriler ile test edilmiştir. Modellerin performansını karşılaştırmak amacı ile karekök ortalama hata $(\mathrm{KOH})$ ve determinasyon katsayıları $\left(\mathrm{R}^{2}\right)$ hesaplanmış olup en iyi sonuç hem sıcaklık hem de yağış verilerinin girdi olarak kullanıldığı üçüncü modelden elde edilmiştir.

Anahtar Kelimeler: Bulanık mantık, akım tahmin, yağış, sıcaklık.

\section{The Estimation of Flow Data By Fuzzy Logic Method: Case Study Bendimahi River}

\begin{abstract}
In this study; The monthly average flow data of the Bendimahi River in the Muradiye District of Van Province were estimated by the Fuzzy Logic Method based on the monthly average temperature and monthly total rainfall data of the same district. Three different models have been created in which only temperature, only rainfall and both temperature and rainfall data are used as input and flow is selected as output. The models were prepared using data from 1970-2008 and tested with data from the years 2009, 2010 and 2011. In order to compare the performance of the models, root mean square errors (RMSE) and determination coefficient $\left(R^{2}\right)$ statistics were calculated and the best result was obtained in the third model where both temperature and rainfall were used as inputs.
\end{abstract}

Keywords: Fuzzy logic, flow forecast, rainfall, temperature. 


\section{GíRiş}

Bir akarsuyun akım değerinin bilinmesi hem taşkın önleme projeleri hem su paylaşım modelleri hem de kuraklık döneminde alınacak tedbirler açısından önemlidir. Ancak, uzun yıllar, sürekli ve sağlıklı debi ölçümü yapmak iklim şartları, topoğrafik zorluklar veya teknik imkansızlıklar nedeniyle çoğu zaman mümkün olmamaktadır.

Ayrıca suyunu göllere taşıyan akarsuların debileri göl seviyesi değişiminde de önemli rol oynamaktadır. Göl seviyesinde yaşanan ani değişimler göl çevresindeki yerleşim alanlarının, tarım alanlarının ve ulaşım ağlarının kullanımını olumsuz etkilediğinden seviye değişimlerinin önceden tespit edilebilmesi için meteorolojik verilerle akış arasındaki ilişkinin sağlıklı tespit edilmesi gerekmektedir.

$\mathrm{Bu}$ sebeplerle mevcut meteorolojik verileri kullanarak bir akarsuyun akım verisini tahmin etmek özellikle debi ölçümünün çeşitli nedenlerle zor olduğu su kaynaklarının projelendirilmesinde önem kazanmaktadır.

Teorik bir yaklaşım olarak doğan ancak zamanla mühendislik bilimleri, sosyal bilimler, bilgisayar bilimleri, yönetim bilimleri, tıp, meteoroloji ve psikoloji gibi pek çok alanda uygulanmaya başlanan bulanık mantık yöntemi, mevcut veri setlerinden yararlanarak tahmin modelleri oluşturmak amacıyla da kullanılmaktadır.

2000 yılında Hindistan'da yapılan bir çalışmada, rezervuar deposu, giriş akımı ve su talebi giriş verisi, çıkış akımı çıkış verisi olarak belirlenerek rezervuar işletme modeli Bulanık Mantık Yöntemi kullanılarak oluşturulmuştur [1]. Tayvan'da 2001 yılında yapılan çalışmada Da-chia Nehrinin iki ayrı kolunda yer alan istasyonlarda kaydedilen akım verilerinden yararlanılarak bir başka istasyona ait akım verileri Bulanık Mantık ve Yapay Sinir Ağı birleştirilerek oluşturulan modelle tahmin edilmiştir [2]. Benzer bir çalışma 2011 yılında, Kızılırmak Nehri akım tahmin modelini oluşturmak için yapılmış ve Yamula ve Bulakbaşı istasyonları akım verileri kullanılarak, Söğüthan istasyonun akım verileri tahmin edilmiştir [3]. 2001 yılında yapılan çalışmada yağışakım modeli Bulanık Mantık Yöntemi kullanılarak oluşturulmuş [4]; benzer bir model, Almanya'da, Neckar Nehri için [5], 2005 yılında Hindistan'da Normada havzası için [6], 2006 yılında 6 farklı havza için geliştirilmiştir [7]. 2000 yılında Bangladeş'de su seviyesinin tahmininde uygulanabilirliği araştırılan yöntem [8], ülkemizde yağış verilerinden yararlanarak Van Gölü seviyesinin tahmini [9] için kullanılmıştır. Ayrıca, optimal su paylaşımı problemi [10], nehirlerdeki askı maddesinin modellenmesi [11], akarsu akışı ve katı madde ilişkisinin incelenmesi [12], toprak erozyonu modellemesi [13] gibi çalışmalarda da Bulanık Mantık Yöntemi kullanılmıştır.

Hem dünyada hem de ülkemizde tahmin modeli oluşturmak amacıyla başarı ile uygulanan Bulanık Mantık Yöntemi, bu çalışmada, Van Gölü havzasının en önemli akarsulardan olan Bendimahi Çayının akım verisini, sıcaklık ve yağış verisine bağlı olarak modellemek amacıyla kullanılmıştır. 


\section{MALZEME VE YÖNTEM}

\subsection{Mamdani Tipi Bulanık Çıkarım Sistemi}

Bulanık Mantık yöntemi 1961 yılında Lütfi Asker Zadeh tarafından geliştirilen ve temeli küme ve alt kümelere dayanan bir metottur [14]. Klasik matematikte, bir varlık bir kümenin elemanıdır veya değildir şeklide ifade edilir. Matematiksel ifadede, varlık kümenin elemanı ise "1", kümenin elemanı değil ise "0" değerini alır. Bulanık varlık kümesinde her bir varlık için $(0,1)$ aralığında herhangi bir değer alabilen üyelik derecesi yazılır. Keskin kümelerdeki iyi-kötü, güzel-çirkin, sert-yumuşak gibi ikili değişkenler, bulanık mantıkta biraz iyi, biraz kötü, biraz sert gibi esnek niteleyicilerle yumuşatılarak gerçek dünyaya benzetilir. Pek çok alanda farklı uygulama alanı bulan genel Bulanık Mantık Sistemi Şekil 1'de gösterilmiştir.

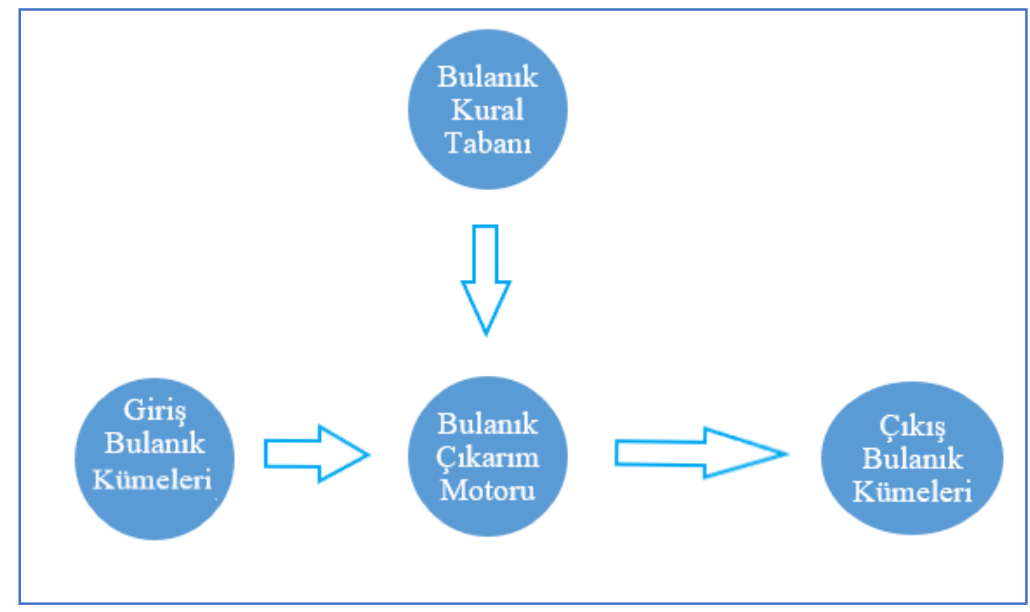

Şekil 1. Genel bulanık sistemi

Bulanık çıkarım sistemlerinden en bilinenleri Mamdani ve Sugeno tipi çıkarım sistemleridir. Şekil 2'de bu çalışmada kullanılan Mamdani çıkarım sisteminin bir örneği yer almaktadır. Yöntemin uygulamasında bulanık kuralların belirlenmesi, üyelik fonksiyonlarını (ÜF) kullanarak girişlerin bulanıklaştırılması, kural kuvveti oluşturmak için bulanıklaşmış girdilerin bulanık kurallara göre birleştirilmesi, kural gücü ile çıktı üyeliği işlevini birleştirerek kuralın sonucunu bulma ve çıktı dağılımını durulaştırma aşamaları takip edilir [15].

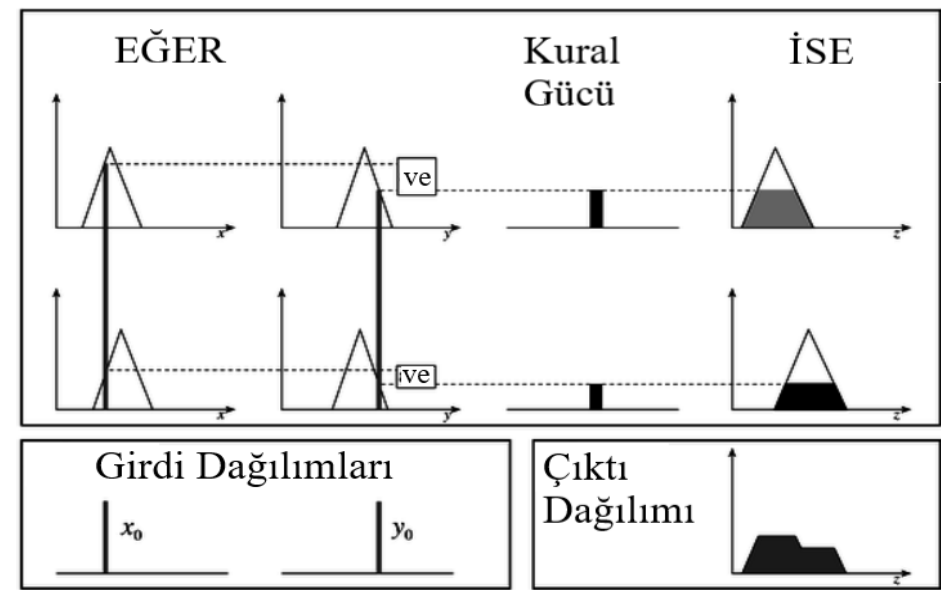

Şekil 2. İki girdi, iki kural için Mamdani Bulanık Çıkarım Sistemi[15] 
Bulanık kurallar, sistemin bir girdiyi sınıflandırma veya bir çıktıyı kontrol etme konusunda nasıl bir karar vermesi gerektiğini açıklayan bir dilbilimsel ifadeler topluluğudur. Bulanık kurallar aşağıdaki biçimde yazilır:

Eğer, (Girdi $1=\ddot{U} F$ 1) ve/veya $($ Girdi $2=\ddot{U} F 2)$ ise $(C ̧ \iota k t \iota n=\ddot{U} F n)$

Yöntemin son aşaması olan durulaştırma adımında Maksimumun en küçügü, en büyügü, ortalaması, alanın açı ortayı gibi farklı yöntemler mevcuttur. Bu çalışmada kullanılan Sendroid durulaştırma metodu aşağıdaki şekilde uygulanır.

$\mathrm{G}=\frac{\sum_{\mathrm{i}=1}^{\mathrm{n}} y_{i} \mathrm{~m}_{\mathrm{B}}\left(y_{i}\right)}{\sum_{\mathrm{i}=1}^{\mathrm{n}} \mathrm{m}_{\mathrm{B}}\left(y_{i}\right)}$

Burada; $G$ üstü kesilmiş bulanık çıktı seti $B$ 'nin ağırlık merkezini, $m_{B}(y i)$ bulanık çıktı seti $B$ 'deki her bir $y_{i}$ elemanına ait üyelik fonksiyonunun değerini, $n$ eleman sayısını ifade etmektedir.

\section{2 Çalışma Alanı ve Veriler}

Bu çalışma kapsamında, Şekil 3'te gösterilen Van Gölü havzası sınırları içerisinde bulunan Bendimahi Çayı üzerinde yer alan ve Devlet Su İşleri tarafından işletilen 2505 nolu Akım Gözlem İstasyonunun (AGİ) aylık ortalama akım verileri çıkış bulanık kümesi olarak seçilmiştir. Giriş verisi olarak, aynı bölgede bulunan ve Meteoroloji Genel Müdürlüğü tarafından işletilen 17786 nolu Muradiye istasyonuna ait aylık ortalama sıcaklık ve aylık toplam yağış verileri seçilmiştir.

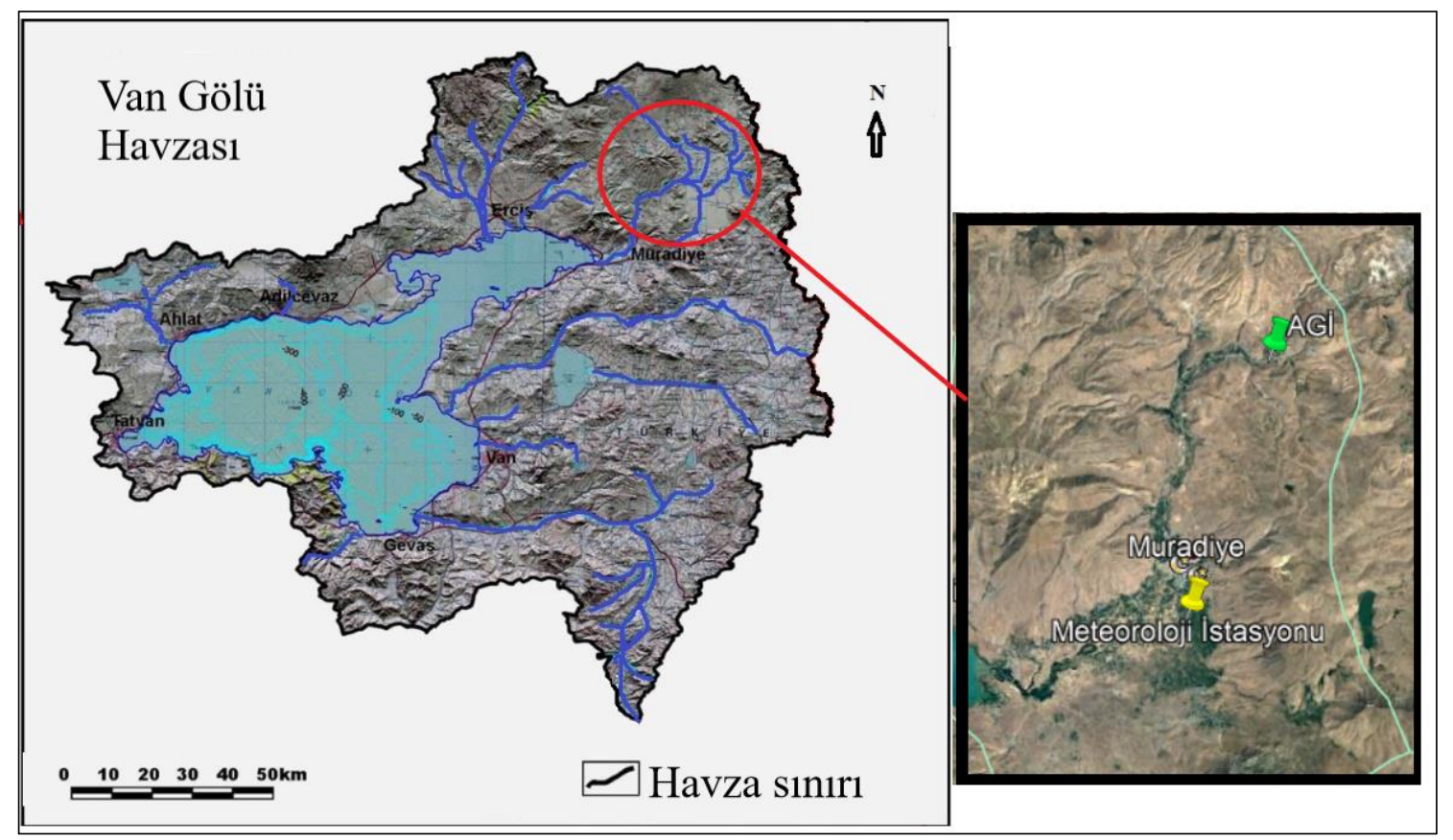

Şekil 3. Çalışma alanı ve istasyonlar

En iyi sonuca ulaşmak amacıyla üç farklı model oluşturulmuştur. İlk modelde sadece sıcaklık değişkeni, ikinci modelde sadece yağış değişkeni, son modelde ise sıcaklık ve yağış değişkenleri birlikte girdi kümesi, akım verisi çıktı kümesi olarak belirlenmiş ve Mamdani tipi çıkarım motoru kullanılmıştır (Şekil 4). 


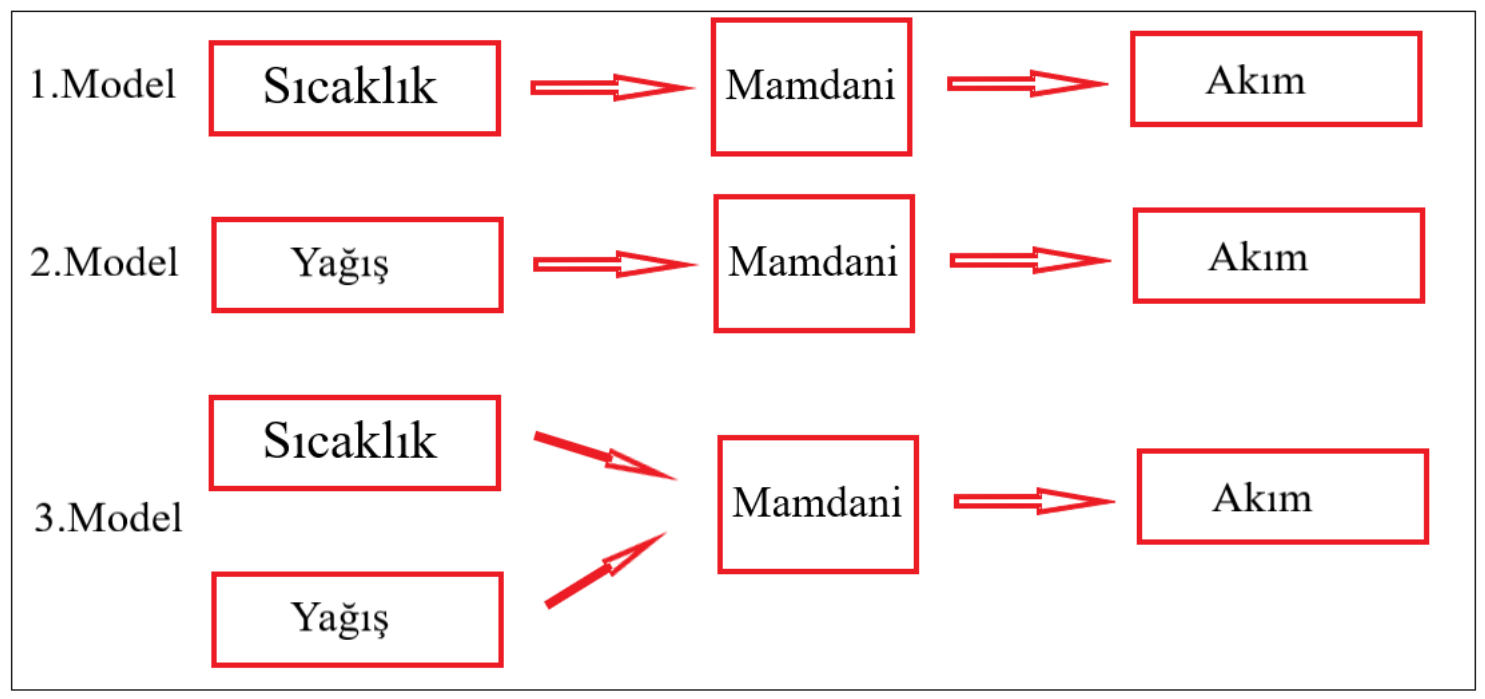

Şekil 4. Oluşturulan modeller

$\mathrm{Bu}$ çalışmada, her üç modelde de üyelik fonksiyonlarını oluşturmak ve kuralları yazmak için 1970-2008 yılları arasına ait veriler kullanılmıştır. İlk modelde giriş değişkeni olarak seçilen ve $-15,+30^{\circ} \mathrm{C}$ aralığında değişen sıcaklık verileri için 10 adet gauss tipi üyelik fonksiyonu yazılmıştır. Çıkış değişkeni olan ve 0-50 $\mathrm{m}^{3} / \mathrm{s}$ aralığında değişen akım verileri için de 5 adet gauss tipi üyelik fonksiyonu yazılmıştır. Her bir ayın karakterini yansıtacak ortalama değerler dikkate alınarak 10 adet kural yazılmıştır. Örneğin $-5{ }^{\circ} \mathrm{C}$ değeriyle yılın en soğuk ayı olan ocak ayı için kural yazılırken ocak ayı ortalama akım değeri olan $5.5 \mathrm{~m}^{3} / \mathrm{s}$ değeri dikkate alınmıştır. En sıcak aylar olan temmuz ve ağustos aylarının akım değerleri ve sıcaklık değerleri birbirlerine yakın olduğundan bu iki ay için tek kural yazmak yeterli olmuştur. Yil içinde 5 ila $10 \mathrm{~m}^{3} / \mathrm{s}$ arasında salınım gösteren akım değerleri, nisan ve mayıs aylarında sıcaklıkların artması ve karların erimesi sonucu ani bir sıçrama ile ortalaması $25-30 \mathrm{~m}^{3} / \mathrm{s}$ olan değerlere ulaşmaktadır. Bu iki aya ait ortalama sıcaklık değerleri için bu sıçramayı yansıtacak şekilde kural yazılmıştır. Ancak, ortalama sıcaklığ $7.5^{\circ} \mathrm{C}$ olan nisan ve $12.5 \mathrm{~m}^{3} / \mathrm{s}$ olan mayıs aylarında, ekim ayının karakteristiğini yansıtan ve bu sebeple ekim ayı akım değeri olan $5.5 \mathrm{~m}^{3} / \mathrm{s}$ için kural yazılmış olan $10{ }^{\circ} \mathrm{C}$ değeri ölçüldüğünde model söz konusu sıçramayı yansitamamaktadir.

İkinci modelde 0 ila $160 \mathrm{~kg} / \mathrm{m}^{2}$ aralığında değişen aylık toplam yağış verileri için 9 adet gauss tipi üyelik fonksiyonu yazılarak 9 adet kural tanımlanmıştır. En az yağışı alan ağustos ve temmuz ayları akım değerlerinde de birbirlerine yakın sonuçlar verdiğinden iki ay için tek kural yeterli olurken, bu iki aya nispeten biraz daha fazla yağış alan eylül ayı için ilave bir kural daha yazılmıştır. Bazı ayların yağış değerleri birbirlerine yakın olmasına rağmen akım değerlerindeki farkı yansıtabilmek amacıyla ayrı ayrı üyelik fonksiyonu oluşturulup ayrı ayrı kural yazılmıştır. En fazla yağış ortalamasına ve akım miktarına sahip olan nisan ve mayıs ayları için de ayrı kurallar yazılmıştır. Kasım ve mart aylarının yağış ortalaması hemen hemen aynı iken mart ayı akım değeri kasım ayına göre daha yüksek olduğundan kural yazarken fazla hataya sebep olmamak amacıyla iki ayın ortalaması dikkate alınarak kural yazılmıştır. Kurallar ayların karakterini yansıtacak ortalama değerler üzerinden yazıldığından örneğin ekim ayının karakterini yansıtan yağış değerine nisan ayında rastlandığında modelde hata payı yüksek olmaktadır.

Son modelde, yağış ve sıcaklık verileri girdi, akım verileri çıktı olarak alınmıştır. Böylece aynı yağışın veya sıcaklığın farklı karakterdeki aylarda ölçülmesi durumunda yaşanan sorunlar en aza indirilmiştir. Örneğin aynı yağış ortalamasına sahip kasım ve mart aylarında ikinci modelde sorun yaşanırken sıcaklık değerleri birbirinden çok farklı olduğu için son modelde hata payı daha az olmuştur. Ortalama $10{ }^{\circ} \mathrm{C}$ değeri hem 
ekim hem de nisan ve mayıs aylarında ölçülebilen bir değer olduğundan mayıs ve ekim ayları yağış ortalamaları da çok yakın olduğundan üyelik fonksiyonu sayısı ve kural sayısı arttırılarak hata payı azaltılmaya çalışılmıştır. Toplamda 12 adet sıcaklık üyelik fonksiyonu, 7 adet yağış üyelik fonksiyonu ve 9 adet akım üyelik fonksiyonu tanımlanıp 54 adet kural yazılarak model oluşturulmuştur.

Oluşturulan 3 Mamdani tipi Bulanık Model, Matlab programında çalıştırılmış ve 2009 ve 2010 ve 2011 yılları için aylık ortalama akım verileri tahmin edilmiştir. Modellerin performanslarını değerlendirmek için karekök ortalama hata $(\mathrm{KOH})$ ve determinasyon katsayısı $\left(\mathrm{R}^{2}\right)$ değerleri sirasıyla formül 2 ve 3 kullanılarak hesaplanmıştır.

$$
\begin{aligned}
& \mathrm{KOH}=\sqrt{\frac{1}{\mathrm{n}}} \sum_{\mathrm{i}=1}^{\mathrm{n}}\left(\mathrm{f}_{\text {igerçek }}-\mathrm{f}_{\text {imodel }}\right)^{2} \\
& R^{2}=1-\frac{\sum_{i=1}^{n}\left(f_{\text {igerçek }}-f_{\text {imodel }}\right)^{2}}{\sum_{i=1}^{n}\left(f_{\text {igerçek }}-f_{\text {iort }}\right)^{2}}
\end{aligned}
$$

Burada; $n$ tahmin edilen veri sayısını, $f_{\text {igerçek }}$ ölçüm akım değerini, $f_{\text {imodel }}$ tahmin edilen akım değerini, $f_{\text {iort }}$ : ortalama akım değerini ifade etmektedir.

\section{BULGULAR VE TARTIŞMA}

1970 ve 2008 yılları arası veriler incelenerek oluşturulan modeller kullanılarak 2009, 2010 ve 2011 yıllarına ait akım verileri tahmin edilmiştir.

Sadece sıcaklık verisi girdi olarak seçilen ilk modelden elde edilen tahmin sonuçları ve ölçüm değerlerini gösteren grafik Şekil 5'te yer almaktadır. Grafikten anlaşılacağı üzere, nisan ve mayıs ayının karakterini yansıtacak şekilde kural yazılan sıcaklık değerinin 2011 yılı ekim ayında ölçülmesi sonucu, model akım değerini gerçek değerin çok üzerinde tahmin etmiştir. Modelin performansını ölçmek amaçlı yapılan hesaplama sonucu $\mathrm{KOH}$ değeri $3.82 \mathrm{~m}^{3} / \mathrm{s}, \mathrm{R}^{2}$ değeri 0.78 olarak bulunmuştur.

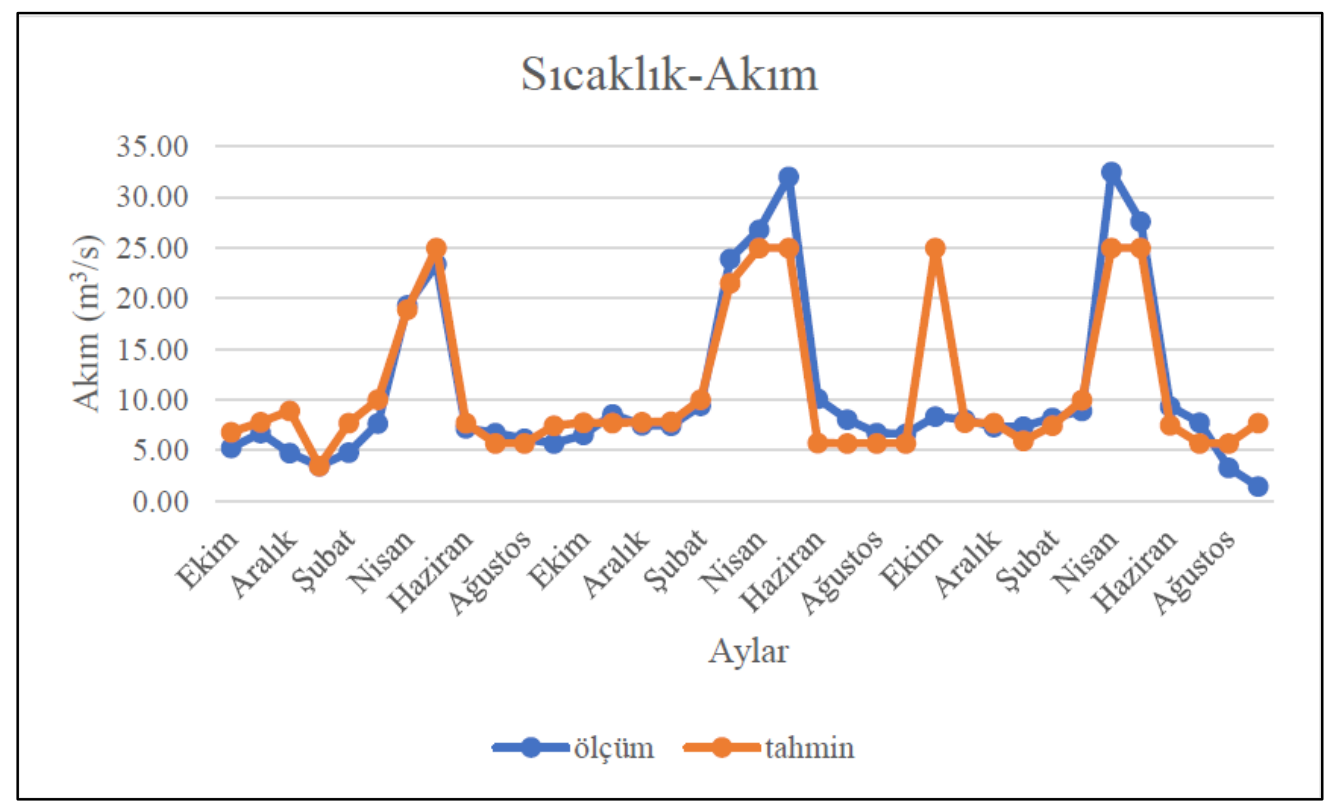

Şekil 5. Sıcaklık verilerine bağlı akım tahmin sonuçları 
Sadece yağış verisi girdi olarak seçilen ikinci modelden elde edilen tahmin sonuçları ve ölçüm değerlerini gösteren grafik Şekil 6'da yer almaktadır. Geçmiş yıllara ait veriler incelendiğinde ekim ayında yağış değerinde yaşanan değişimlerin akım verilerinde ciddi bir değişime sebep olmadığı görülmüştür. Bu durum bu dönemde zemin neminin az olması sebebiyle yağışın akışa geçmediği zemine sızdığı şeklinde yorumlanabilir. Ayrıca kış aylarında yaşanan düşük sıcaklılar sebebiyle don olayları yaşanması bu aylarda yağış ve akış arasında kural yazımında sıkıntı yaşanmasına sebep olmuştur. Nisan ve mayıs aylarında diğer aylarda görülebilen sıcaklık ve yağış değerleri ölçülmesine rağmen akım değerinin nispeten fazla olması sicaklıkların artmasıyla birlikte karların erimesinden kaynaklanmaktadır ve bu durum da kural yazımını zorlaştırmıştır. Genelde nisan ve mayıs aylarında ölçülen 75 ve üzeri yağış değerlerinin özellikle 2009 yılında sonbahar ve kış aylarında da ölçülmesi sonucu bu aylarda modelde ciddi hatalar meydana gelmiştir. $\mathrm{Bu}$ sebeple, ilk modelde $3.82 \mathrm{~m}^{3} / \mathrm{s}$ olarak hesaplanan $\mathrm{KOH}$ değeri ikinci modelde $9.39 \mathrm{~m}^{3} / \mathrm{s}$ olarak hesaplanırken $\mathrm{R}^{2}$ değeri 0.78 değerinden -0.31 değerine düşmüştür. Bu değerler, yağış verisinin tek girdi kümesi olarak seçilmesinin Bendimahi Çayı için uygun olmadığını göstermiştir. Meteorolojik veri olarak sadece yağış verisi kullanılmak istenirse ay verisi ikinci girdi kümesi olarak seçilerek hata payını azaltmak yoluna gidilebilir.

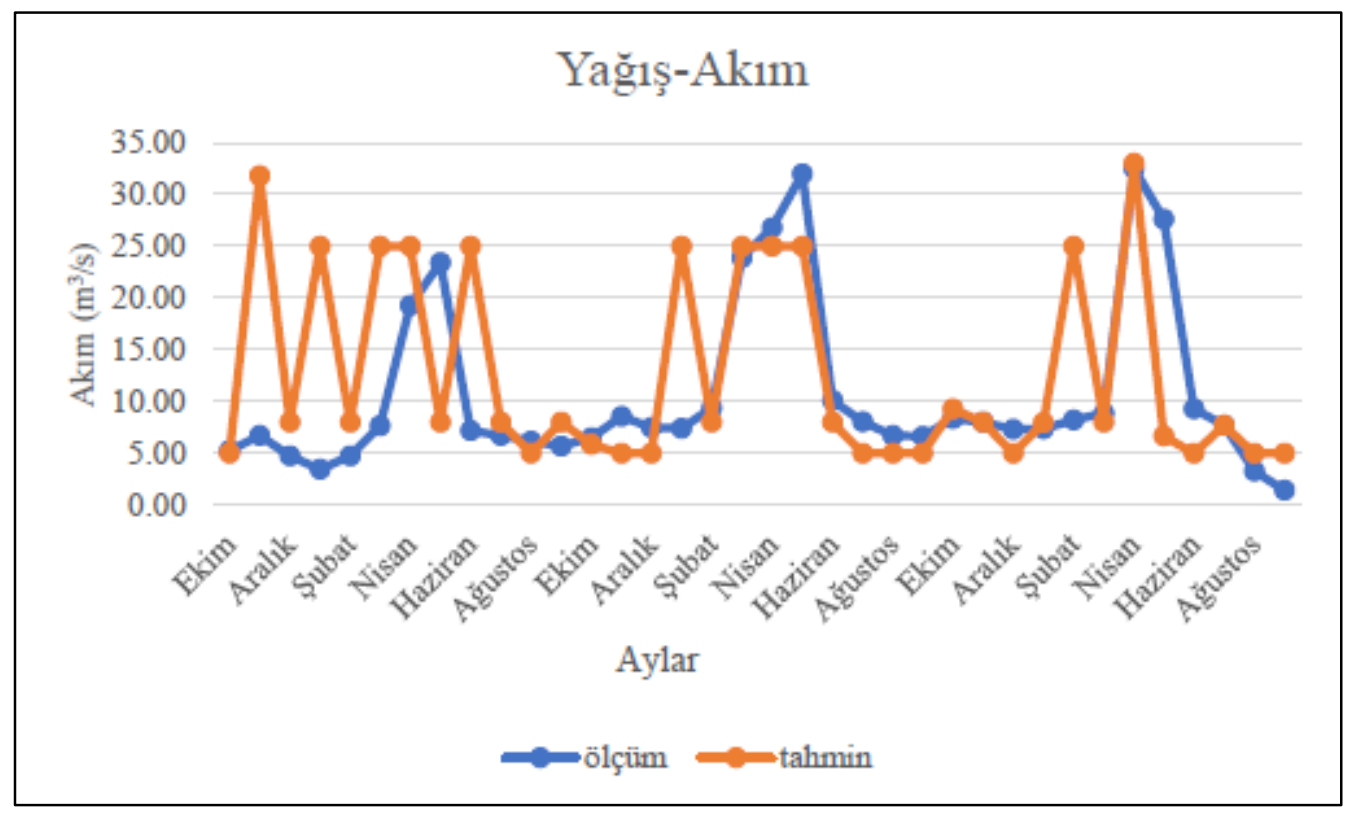

Şekil 6. Yağış verilerine bağlı akım tahmin sonuçları.

Hem sıcaklık hem de yağış verisi girdi olarak seçilen son modelden elde edilen tahmin sonuçları ve ölçüm değerlerini gösteren grafik Şekil 7'de yer almaktadır. Sıcaklık ve yağışın aynı anda girdi olarak alınması 
model 1 ve 2 de yaşanan sorunların yaşanmasının önüne geçerek hata miktarlarını azaltmış böylece $\mathrm{KOH}$ değeri $1.61 \mathrm{~m}^{3} / \mathrm{s}, \mathrm{R}^{2}$ değeri 0.96 olarak hesaplanmıştır.

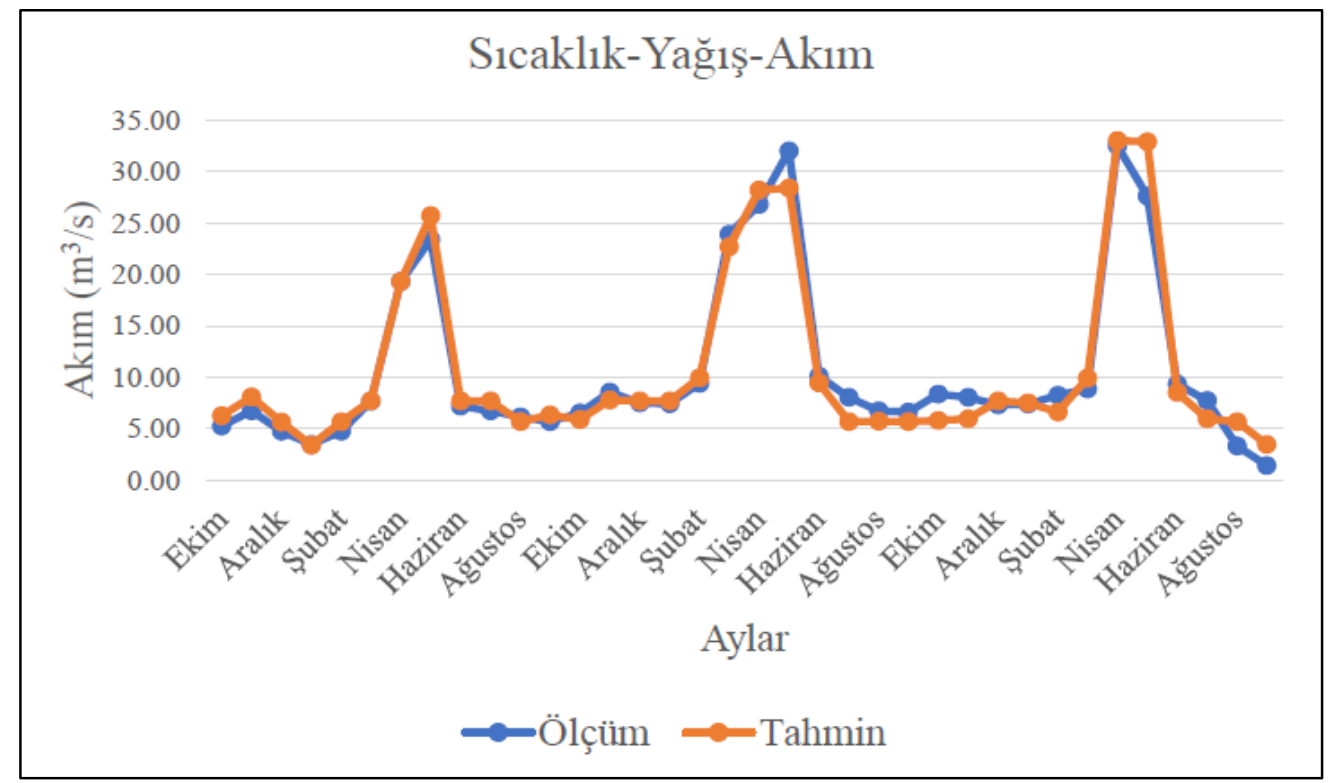

Şekil 7. Sıcaklık ve yağış verilerine bağlı akım tahmin sonuçları

Üç modelde elde edilen sonuçların bir arada değerlendirilebilmesi için, ikinci modelde ölçüm ve tahmin değerleri arasındaki dalgalanmanın en fazla yaşandığı 2009 yılına ait değerler Tablo 1'de gösterilmiştir.

Tablo 1. Her bir model için 2009 yılına ait ölçüm ve tahmin sonuçları.

\begin{tabular}{|c|c|c|c|c|c|c|c|c|c|c|c|c|}
\hline \multirow{2}{*}{ Veri } & \multicolumn{12}{|c|}{2009} \\
\hline & Ekim & Kasım & Aralık & Ocak & Şubat & Mart & Nisan & Mayıs & Haziran & Temmuz & Ăgustos & Eylül \\
\hline \multicolumn{13}{|c|}{ 1. Model } \\
\hline $\begin{array}{l}\text { Ölçülen } \\
\text { akım }\end{array}$ & 5.27 & 6.73 & 4.76 & 3.46 & 4.77 & 7.68 & 19.30 & 23.40 & 7.21 & 6.74 & 6.17 & 5.71 \\
\hline $\begin{array}{l}\text { Tahmin } \\
\text { akım }\end{array}$ & 6.81 & 7.8 & 8.89 & 3.45 & 7.7 & 10 & 18.9 & 25 & 7.69 & 5.7 & 5.69 & 7.45 \\
\hline Hata & 1.54 & 1.07 & 4.13 & 0.01 & 2.93 & 2.32 & 0.40 & 1.60 & 0.48 & 1.04 & 0.48 & 1.74 \\
\hline \multicolumn{13}{|c|}{ 2. Model } \\
\hline $\begin{array}{l}\text { Ölçülen } \\
\text { akım }\end{array}$ & 5.27 & 6.73 & 4.76 & 3.46 & 4.77 & 7.68 & 19.30 & 23.40 & 7.21 & 6.74 & 6.17 & 5.71 \\
\hline $\begin{array}{l}\text { Tahmin } \\
\text { akım }\end{array}$ & 5 & 31.8 & 8 & 25 & 8 & 25 & 25 & 8 & 25 & 8 & 5 & 8 \\
\hline Hata & 0.27 & 25.07 & 3.24 & 21.5 & 3.23 & 17.3 & 5.70 & 15.40 & 17.79 & 1.26 & 1.17 & 2.29 \\
\hline \multicolumn{13}{|c|}{ 3. Model } \\
\hline $\begin{array}{l}\text { Ölçülen } \\
\text { akım }\end{array}$ & 5.27 & 6.73 & 4.76 & 3.46 & 4.77 & 7.68 & 19.30 & 23.40 & 7.21 & 6.74 & 6.17 & 5.71 \\
\hline $\begin{array}{l}\text { Tahmin } \\
\text { akım }\end{array}$ & 6.29 & 8.1 & 5.67 & 3.41 & 5.7 & 7.69 & 19.3 & 25.7 & 7.71 & 7.7 & 5.69 & 6.35 \\
\hline Hata & 1.02 & 1.37 & 0.91 & 0.05 & 0.93 & 0.01 & 0.00 & 2.30 & 0.50 & 0.96 & 0.48 & 0.64 \\
\hline
\end{tabular}

Birinci modelde tahmin ve ölçüm akım değerleri arasındaki en büyük fark $4.13 \mathrm{~m}^{3} / \mathrm{s}$ değeri ile aralık ayında, ikinci modelde $25.07 \mathrm{~m}^{3} / \mathrm{s}$ değeriyle kasım ayında ve üçüncü modelde $2.30 \mathrm{~m}^{3} / \mathrm{s}$ olarak mayıs ayında belirlenmiştir. 


\section{SONUÇ}

$\mathrm{Bu}$ çalışma kapsamında, düzenli ölçüm yapılması meteorolojik verilere nispeten daha zor olan akım verisinin tahmin modelinin meteorolojik verilere bağlı olarak oluşturulması hedeflenmiştir. En iyi sonuca ulaşmak amacıyla üç farklı model oluşturularak modellerin performansları karşılaştırılmıştır. İlk iki modelde sadece sıcaklık ve sadece yağış verisi girdi olarak seçilirken üçüncü modelde her ikisi birden girdi olarak seçilmiştir. Sonuçlar incelendiğinde, son modelde hem sıcaklık hem de yağış verileri dikkate alınarak kurallar yazıldığından sadece tek girdiye göre kural yazılan diğer iki modele göre daha iyi sonuç alındığ

Hazırlanan model sayesinde akarsuda, herhangi bir ayda ya da yılda iklim koşulları, ulaşım zorluğu, teknik aksaklıklar ve arızalar sebebiyle ölçüm yapılamaması durumunda eksik verilerin tamamlanması mümkün olacaktır.

Aynı bölgede, aynı zaman diliminde düzenli ölçüm yapılmış kar yağışı, buharlaşma, nem verisi gibi üçüncü veya dördüncü girdi parametresi de belirlenerek modelin hassasiyeti arttırılarak hata pay1 azaltılabilir. Ancak çalışma alanında düzenli veriye sahip üç parametre olduğundan model iki girdi bir çıtı olarak tasarlanmıştır.

\section{REFERANSLAR}

[1] Panigrahi, D.P. ve Mujumdar, P.P., (2000). "Reservoir Operation Modelling with Fuzzy Logic", Water Resources Management, 14, 89-109.

[2] Chang, F.J., Hu, H.F., ve Chen, Y.C., (2001). "Counter propagation fuzzy-neural network for river flow reconstruction" Hydrological Processes, 15, 219-232.

[3] Köse, M., Terzi, Ö., İlker, A. ve Ergin, G., (2011). "Uyarlamalı A ̆g Tabanlı Bulanık Mantık Çıkarım Sistemi İle Kızılırmak Nehri'nin Akım Tahmini”, 6th International Advanced Technologies Symposium (IATS'11), 161-165, Elazı̆̆,

[4] Ertunga, C.Ö., ve Duckstein, L., (2001). "Fuzzy conceptual rainfall-runoff models", Journal of Hydrology, 253, 41-68.

[5] Hundecha, Y., Bardossy, A. ve Theisen, H.W., (2001). "Development of a fuzzy logic-based rainfall-runoff model", Hydrological Sciences, 46, 3, 363-376.

[6] Nayak, P.C., Sudheer, K.P. ve Ramasastri K.S. (2005). "Fuzzy computing based rainfall-runoff model for real time flood forecasting", Hydrological Process, 19, 955-968.

[7] Jacquin, A.P., ve Shamseldin, A.Y., (2006). "Development of rainfall-runoff models using TakagiSugeno fuzzy inference systems", Journal of Hydrology, 329, 154-173

[8] Liong, S.Y., Lim, W.H., Kojiri, T., ve Hori, T., (2000). "Advance Flood forecasting for Flood stricken Bangladesh with a fuzzy reasoning method", Hydrological Process, 14, 431-448.

[9] Altunkaynak, A. ve Şen, Z., (2007). "Fuzzy logic model of lake water level fluctuations in Lake Van, Turkey", Theoretical and Applied Climatolgy, 90, 227-233.

[10] Kindler, J., (1992). "Rationalizing water requirements with aid of fuzzy allocation model.” Journal of Water Resources Planning Management, 118, 3, 308-323.

[11] Kişi, Ö., Karahan, M.E. ve Şen, Z., (2003). "Nehirlerdeki askı maddesi miktarının bulanık mantık ile modellenmesi", İstanbul Teknik Üniversitesi Dergisi, 2, 3, 43-54.

[12] Fırat, M., (2007). "Sinirsel bulanık mantık yaklaşımı ile havza modellemesi", Doktora Tezi, Pamukkale Üniversitesi, Fen Bilimleri Enstitüsü, Denizli,

[13] Mitra, B., Scott, H.D, Dixon J.C. ve Mckimmey, J.M., (1998). "Application of fuzzy logic to the prediction of soil erosion in a large watershed", Geoderma, 86, 183-209.

[14] Zadeh, L.A., (1965). "Fuzzy Sets", Information and Control, 8, 338-353.

[15] Princeton Universitiy, (2019), "Fuzzy İnference Systems", Departmant of Computer Siciens, http://www.cs.princeton.edu/courses/archive/fall07/cos436/HIDDEN/Knapp/fuzzy004.htm 
Geliş/Received: 31 May 2019/31 May 2019

Kabul Ediliş/Accepted: 30 A ̆̆u 2019/30 Aug 2019 